\title{
Transformation and utilization of slowly biodegradable organic matters in biological sewage treatment of anaerobic anoxic oxic systems
}

\author{
Q.H. Zhang ${ }^{\mathrm{a}, \mathrm{b}}$, P.K. Jin ${ }^{\mathrm{b}}$, H.H. Ngo ${ }^{\mathrm{c}, *}$, X. Shi ${ }^{\mathrm{d}}$, W.S. Guo ${ }^{\mathrm{c}}$, S.J. Yang ${ }^{\mathrm{d}}$, X.C. Wang ${ }^{\mathrm{a}, \mathrm{b}}$, X. Wang $^{\mathrm{e}}$, M. Dzakpasu ${ }^{\mathrm{d}}$, \\ W.N. Yang ${ }^{\mathrm{d}}$, L. Yang ${ }^{\mathrm{f}}$ \\ ${ }^{a}$ Key Lab of Northwest Water Resource, Environment and Ecology, Ministry of Education, Xi'an University of Architecture and Technology, Xi'an 710055, China \\ ${ }^{\mathrm{b}}$ International Science \& Technology Cooperation Center for Urban Alternative Water Resources Development, Xi'an 710055, China \\ ' Centre for Technology in Water and Wastewater, School of Civil and Environmental Engineering, University of Technology, Sydney, PO Box 123, NSW 2007, Australia \\ ${ }^{\mathrm{d}}$ School of Environmental and Municipal Engineering, Xi'an University of Architecture and Technology, Xi'an 710055, China \\ ${ }^{\mathrm{e}}$ Research Center for Eco-Envrionmental Sciences, Chinese Academy of Sciences, Beijing 100085, China \\ ${ }_{\mathrm{f}}^{\mathrm{D}}$ Department of Materials Science and Engineering, Monash University, Clayton, VIC 3800, Australia
}

\section{H I G H L I G H T S}

- SBOM play a decisive role in sewage treatment plants.

- Anaerobic/anoxic effective controlling can enhance the conversion rate of SBOM.

- $65 \%$ SBOM can be transformed into more readily biologically utilizable substrates.

- Long hours of microbial reaction increased the micromolecular substances.

\section{A R T I C L E I N F O}

\section{Article history:}

Received 28 April 2016

Received in revised form 16 June 2016

Accepted 17 June 2016

Available online 18 June 2016

\section{Keywords:}

Slowly biodegradable organic matters (SBOM)

Carbon sources

Anaerobic anoxic oxic (AAO)

Dissolved organic matters (DOM)
G R A P H I C A L A B S T R A C T

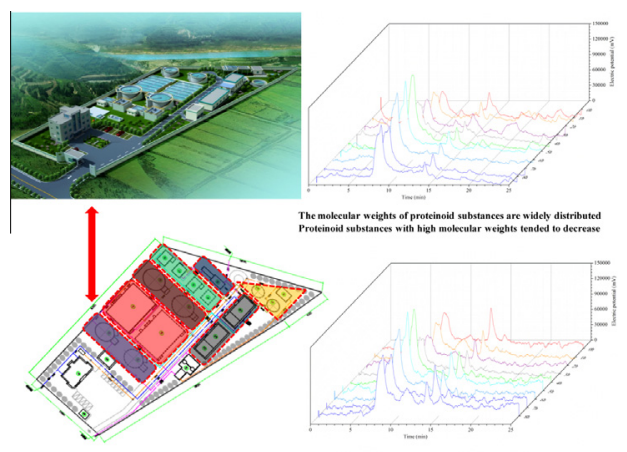

\begin{abstract}
A B S T R A C T
This study examined the distribution of carbon sources in two anaerobic anoxic oxic (AAO) sewage treatment plants in Xi'an and investigated the transformation characteristics and utilization potential of slowly biodegradable organic matters (SBOM). Results indicated under anaerobic and aerobic conditions, SBOM could be transformed at a rate of $65 \%$ in $8 \mathrm{~h}$ into more readily biologically utilizable substrates such as volatile fatty acids (VFAs), polysaccharides and proteins. Additionally, non-biodegradable humus-type substances which are difficult to biodegrade and readily accumulate, were also generated. These products could be further hydrolyzed to aldehyde and ketone compounds and then transformed into substances with significant oxygen-containing functional groups and utilized subsequently. The molecular weights of proteinoid substances had a wide distribution and tended to decrease over time. Long hours of microbial reaction increased the proportion of micromolecular substances. This particular increase generated significant bioavailability, which can greatly improve the efficiency of nitrogen removal.
\end{abstract}

(c) 2016 Elsevier Ltd. All rights reserved.

\footnotetext{
* Corresponding author.

E-mail addresses: h.ngo@uts.edu.au, ngohuuhao121@gmail.com (H.H. Ngo).
}

\section{Introduction}

As the major pollutants of urban sewage treatment plants, organic pollutants are typically characterized by chemical oxygen 
demand (COD) or biological oxygen demand (BOD). However, differences in sewage composition cannot be described by COD. Currently, the Activated Sludge Models (ASMs) as suggested by the International Water Association are the most widely recognized methods for characterizing COD components (Ikumi et al., 2014; Wichern et al., 2006; Wu et al., 2016). The quantitative characterization of these components is required for the application of ASMs. Rapidly biodegradable COD (RBCOD,Ss) and slowly biodegradable COD (SBCOD,Xs) components are the most important components of ASMs, which are directly correlated with the dynamic characteristics of microbe proliferation, oxygen utilization and removal of nutrients (McDowell et al., 2006; Tran et al., 2015).

Compared with domestic wastewater, activated sludge more rapidly adsorbs colloidal matters in sanitary sewage in order to remove them from the liquid phase (Ji et al., 2010). These colloidal matters and other particulate biodegradable substances are considered to constitute Slowly biodegradable organic matters (SBOM) (Hong et al., 2005; Chon et al., 2013; Jin et al., 2014, 2015). According to the ASMs, organic matter under $14.7 \mathrm{mg}$ COD/g (sludge.h) are SBOM. Based on dissolved-oxygen curve slope variations (Jin et al., 2015), single-OUR respirometry is recommended for acquiring the value of each component. Roeleveld and van Loosdrecht (2002) proposed a BOD-time function curve to determine the content of SBOM; the values of biodegradable components can be determined by analyzing the curve. Raunkjaer et al. (1994) in their analysis indicated that organic pollutants in sewage were primarily proteins, saccharides and aliphatics, accounting for at least $78 \%$ of the total COD. Proteins, saccharides and aliphatics are macromolecular organic matter, and most of them also constitute SBOM.

In sewage treatment, hydrolysis is the primary and ratelimiting step for macromolecular organic matter removal (Jin et al., 2014; Lee et al., 2008; Zhu et al., 2009). In a biological treatment process system, the hydrolysis reaction rate is limited by the supply of available carbon in the system, i.e. the rate of hydrolysis controls, denitrification reactions, phosphorus release rates, and phosphorus removal systems (Gao et al., 2010; Ma et al., 2002; Wang et al., 2013). Therefore, hydrolysis determines the nitrogen and phosphorus removal efficiencies and guides the selection of an appropriate microbial community (Jensen et al., 2009). SBOM consist of a variety of components that are too large to be directly absorbed by cells. These components can be metabolized if they are firstly hydrolyzed into smaller substances by extracellular hydrolytic enzymes. Secondly, SBOM have particle diameters and structures that vary in size, and are only utilized by microbes after a complicated series of reactions, such as adsorption and hydrolysis, prior to storage in a sewage treatment system (Liu et al., 2012, 2011).

Suspended pollutants in urban sewage are characterized by their slow biodegradation (Jordao et al., 2002; Liu et al., 2015; Munoz et al., 2009). However, a few issues need to be resolved before adapting microbes for implementation in high suspended solids (SS) urban sewage treatment plants. For example, the mechanism by which microbes utilize slowly biodegradable components needs to be addressed. More specifically, the transformation of slowly biodegradable components during the urban sewage treatment process should be characterized to determine whether the components can be adopted as supplemental carbon sources for sewage treatment (Tas et al., 2009; Ubay Cokgor et al., 2009). Thus, this paper examined the distribution of carbon sources in Xi'an Sewage Treatment Plant, which is located in China, and evaluated the transformation characteristics and utilization potential of SBOM. The results of this study will guide the decisions for upgrading sewage treatment plants to meet more stringent sewage treatment standards.

\section{Materials and methods}

\subsection{Experimental materials}

Several materials used in this study are: a $0.45-\mu \mathrm{m}$ cellulose acetate filter membrane, a sulfuric acid/silver sulfate solution, an ammonium ferrous sulfate solution, anthrone reagent, glucose, a bull serum albumin (BSA) standard solution, an alkaline copper sulfate solution, allyl thiourea (ATU) reagent, a dissolved oxygen meter, a magnetic stirrer set, and a thermostatic water bath.

\subsection{Experimental methods}

\subsubsection{Determination of oxygen uptake rate (OUR)}

A batch OUR respirometry method was used. To measure the oxygen consumption rate in a simulation test, $1 \mathrm{~L}$ of mixed sewage/sludge solution was required. One liter of sewage sample and sludge at a sewage-to-sludge ratio of 3:1 were added into an airtight batch reactor. The sludge was thoroughly aerated to maintain endogenous respiration and was then elutriated three times with VSS sludge at $2500 \mathrm{mg} / \mathrm{L}$. A nitrification inhibitor ATU was then added to inhibit the activities of autotrophic bacteria at a constant temperature of $20^{\circ} \mathrm{C}$. The changes in dissolved oxygen concentration were monitored using a dissolved oxygen meter so that an oxygen consumption rate curve could be developed.

\subsubsection{Determination of $C O D$}

The COD was determined using a potassium dichromate method. A sewage sample was filtered through a $0.45-\mu \mathrm{m}$ membrane to measure the total sewage and dissolved COD. The particulate COD was derived by subtracting the dissolved COD from the total sewage COD.

\subsubsection{Determination of VFAs}

The VFAs were determined by gas chromatography. Briefly, a sewage sample was filtered through a $0.45-\mu \mathrm{m}$ membrane. $250 \mu \mathrm{L}$ of methanoic acid (as stationary liquid) was then added to $5 \mathrm{~mL}$ of the filtered sewage sample. The solution mixture was sampled by a gas chromatograph using split sampling at a volume of $1 \mu \mathrm{L}$ and a split ratio of $10: 1$. The temperatures of the sample injector and detector were $100{ }^{\circ} \mathrm{C}$ and $250{ }^{\circ} \mathrm{C}$, respectively. The sampling schedule was as follows: at retention time $2 \mathrm{~min}$, increase the temperature from $100^{\circ} \mathrm{C}$ to $160^{\circ} \mathrm{C}$ at a heating rate of $3{ }^{\circ} \mathrm{C} \mathrm{min}^{-1}$ and maintain for $2 \mathrm{~min}$.

\subsubsection{D fluorescence spectrometry}

An FP6500 fluorescence spectrophotometer (JASCO) was used at an excitation wavelength range of $220-480 \mathrm{~nm}$ and an emission wavelength range of $280-570 \mathrm{~nm}$ at scanning intervals of $5 \mathrm{~nm}$ and $2 \mathrm{~nm}$, respectively, at a scanning speed of $2000 \mathrm{~nm} / \mathrm{min}$. A $3 \mathrm{D}$ fluorescence spectrum was acquired using MATLAB software.

\subsubsection{Determination of polysaccharides and protein}

The anthrone method was employed to measure the level of polysaccharides (Katsuki Kimura et al., 2015), while the Lowry method served to measure the level of proteins (Nikos Vakondios et al., 2014).

\subsubsection{UV spectrum}

Dissolved samples were scanned over a wavelength range of 200-600 nm using a TU-1901 double-beam UV-vis spectrophotometer at a wavelength interval of $1 \mathrm{~nm}$ to determine the DOM. The specific ultraviolet absorbance $\operatorname{SUVA}_{254}\left(\mathrm{~L} \mathrm{mg}^{-1} \mathrm{~m}^{-1}\right)$, the $\mathrm{A}_{253} / \mathrm{A}_{203}$ absorbance ratio (at $253 \mathrm{~nm}$ and $203 \mathrm{~nm}$ ), and $\mathrm{E}_{4} / \mathrm{E}_{6}$ absorbance ratio (at $465 \mathrm{~nm}$ and $665 \mathrm{~nm}$ ) were analyzed. 


\subsubsection{Analysis of molecular weight}

A high performance liquid chromatograph (Shimadzu LC2010AHF) and a gel chromatography column (Zenix SEC-100 $7.8 \times 300 \mathrm{~mm} 3 \mu \mathrm{m}$ ) were used. The detection wavelength of the UV detector was $254 \mathrm{~nm}$. The Ex/Em scanning wavelengths of the fluorescence detector were 230/335 and 285/335. The flow rate was $0.8 \mathrm{ml} / \mathrm{min}$ while the sample intake was $20 \mu \mathrm{L}$. A pH 7.0 phosphate buffer served as the mobile phase of the liquid chromatogram, and the standard for reticule determination was polystyrene sulfonic acid sodium salt.

\subsection{Laboratory simulation test}

The main particulate organic matters in the samples were SBOM and inert organic matter. Rapidly biodegradable organic matter (RBOM) accounted for only $5 \%$ of the total content and this can be ignored. It is evident that the composition of inert organic matters rarely changed over a short period. For this reason only SBOM were considered. SBOM served as the carbon source and was obtained from raw sewage generated by Sewage Treatment Plant A. The effluent from a primary sedimentation tank was filtered through a $0.45-\mu \mathrm{m}$ membrane, and the residue was eluted in a small quantity of ultrapure water. The sludge sourced from Plant A was aerated without influent to reach an endogenous respiration level before being rinsed in distilled water to minimize the effects of residual COD. The inoculation sludge and the carbon source were divided into two equal parts and then they were reacted, respectively, under anaerobic (DO $<0.5 \mathrm{mg} / \mathrm{L}$ ) and aerobic (DO $=2 \sim 3 \mathrm{mg} / \mathrm{L}$ ) conditions for $8 \mathrm{~h}$. During the reaction, the reactors' volatile suspended solids (VSS) were maintained at approximately $2500 \mathrm{mg} / \mathrm{L}$ and at temperatures of $20^{\circ} \mathrm{C}$ under slow stirring. The compositional variation of SBOM was observed over time.

\section{Results and discussion}

\subsection{Loss of carbon source in primary treatment systems}

The precipitation and removal of suspended solids in the primary settling tank also result in the loss of large amounts of particulate carbon. This process of particulate carbon loss has been particularly evident in the urban sewage treatment plants in Xi'an, which had higher particulate COD. After treatment in the primary settling tank, a significant decrease in the density of COB was observed and about $20 \% \sim 30 \%$ of organic matter was lost.

The total concentration of lower fatty acid was taken as the standard measurement for volatile fatty acids (VFAs). Therefore, the inflow and outflow concentrations of VFAs in the primary settling tanks of sewage treatment plants $A$ and $B$, both of which employ the AAO process were measured for comparison with the soluble COD concentrations. Changes in the inflow and outflow VFAs of the primary settling tank and the proportion of soluble COD were used to demonstrate the availability of carbon source in the different sewage treatment plants. VFAs are one kind of carbon source utilized in nitrogen and phosphorus removal in biological treatment systems. Phosphorus-accumulating bacteria convert VFAs into PHA under anaerobic conditions, which are subsequently stored in the organisms. Hence, the quantity of VFAs has a significant impact on the efficiency of nitrogen and phosphorus removal.

The difference in concentration of inflow soluble COD between the sewage treatment plants A and B can be attributed mainly to the inflow water quality, the scale of collection area and daily water quality. A minimal amount of soluble COD was lost with the removal of particulate organic matter after treatment in the primary settling tanks of the sewage plants $A$ and $B$, resulting in a slight decrease in the concentration of the soluble COD. Moreover, the concentration of VFAs also decreased (Fig. 1) by $2.54 \mathrm{mg} / \mathrm{L}$ and $1.61 \mathrm{mg} / \mathrm{L}$, respectively in plants $A$ and $B$, about $10 \%$ of which were lost in the primary settling tanks. Furthermore, the results indicate that the amount of available carbon source with high quality was not significant in sewage plants in Xi'an.

Fig. 2 shows changes in the concentrations of RBOM and SBOM in the primary settling tank of plant A over the period from January to October 2015.

Overall, about $30 \%$ of the SBOM were removed after treatment in the primary settling tank. Most of the SBOM existed in particle form, large amounts of which were removed in the primary settling tank with the removal of SS. Moreover, some SBOM were removed along with the sedimentation of floating matter, and thus, some dissolved organic carbon source adsorbed on the particulate matter were removed along with the sedimentation of particulate matter. Drewnowski and Makinia (2011) pointed out that the removal of particulate organic matter in the primary settling tank decreases the anaerobic phosphorus release rate and anoxic phosphorus uptake rate by $14 \%$ and $46 \%$, respectively. Therefore, large amounts of carbon are wasted in the primary settling tank, which intensifies the shortage of carbon source, ultimately impacting the nitrogen and phosphorus removal in the biological tank.

SBOM were the main component of the inflow and outflow of the primary settling tank, most of which existed in the particle form. In the particulate form, organic matter is not readily available to microorganisms in the biotreatment process unless they are hydrolyzed into easily biodegradable components. Findings from this study indicate that most of the organic matter in the inflow water of the sewage plants in Xi'an were SBOM. Nevertheless, part of the organic matter were removed after treatment in the primary settling tanks. The organic matter in the outflow water was also mainly of SBOM. Theoretically, in the removal of phosphorus, phosphorus-accumulating bacteria need a source of highquality carbon (like VFAs) to release phosphorus. Similarly, in the removal of nitrogen, denitrifying bacteria also need a carbon source to achieve denitrification in the anoxic phase, although part of the organic matter would directly affect the denitrification rate of denitrifying bacteria. With most of the organic matter in the primary settling tank existing in the particle form, which is not readily available to microorganisms in the biotreatment process, the nitrogen and phosphorus removal in the biological tank can be severely impacted.

Overall, although the loss of carbon source in the primary settling tank is high, most are slowly biodegradable particulate carbon. On the other hand, the loss of RBOM is minimal. Thus, the

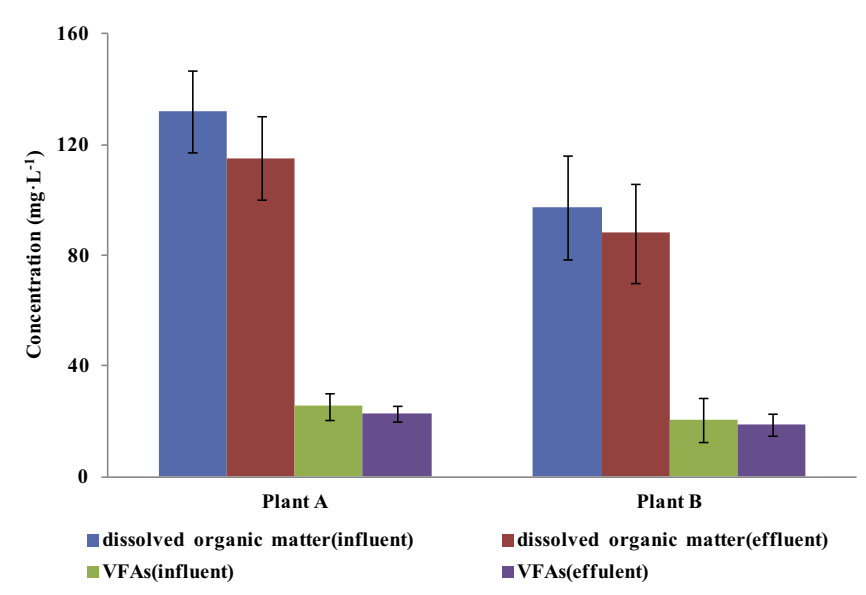

Fig. 1. The concentration of VFAs and dissolved organic matter in the primary settling tank in Plant A and Plant B. 


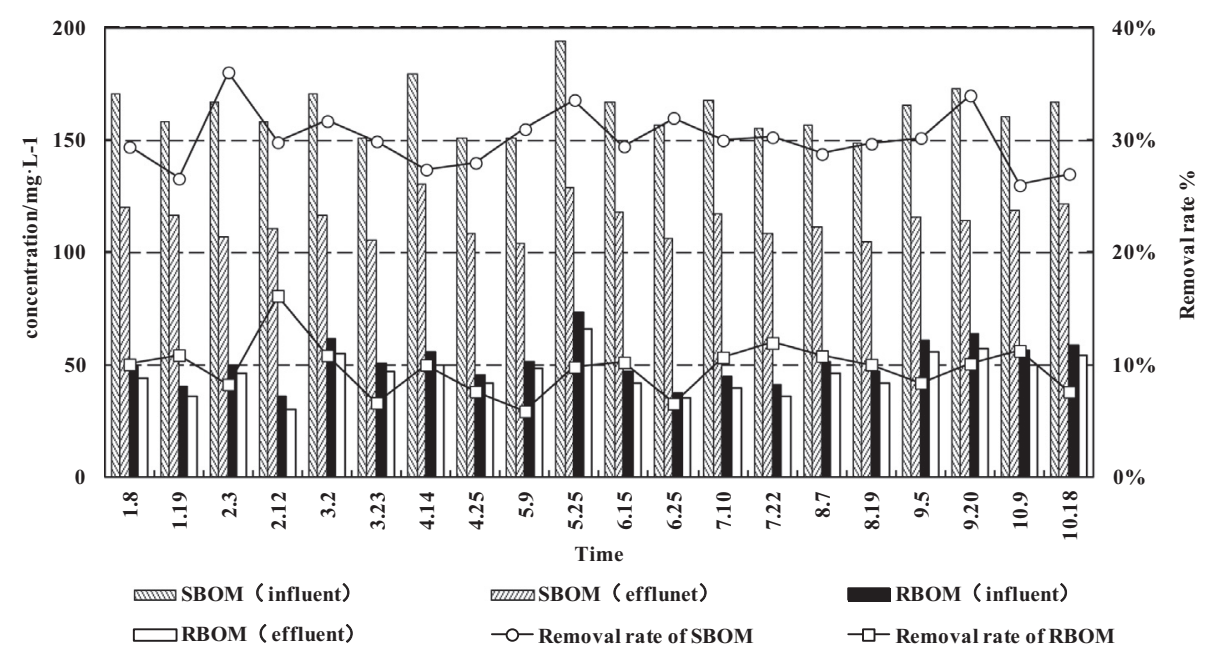

Fig. 2. Change of RBOM and SBOM in the primary settling tank of sewage plant A.

high availability of the particle carbon source decreases the overall loss of carbon source and, hence, minimizing the deficiency of carbon source in the sewage plant.

\subsection{Degradation pathways and utilization of SBOM}

Based on the above transformation and utilization of particulate carbon sources, tests and analyses conducted on SBOM from the Xi'an Sewage Treatment Plant were done. Table 1 summarizes the variation in SBOM along the complete typical $A^{2} / 0$ processes of Plant A and Plant B in Xi'an. As can be seen in Fig. 3, the variation trends regarding SBOM of the two plants are similar, and in fact the concentrations of SBOM decreased during the processes, indicating that SBOM are degradable.

Precipitable substances and floating matter in sewage were removed in a primary sedimentation tank. The content of SBOM decreased significantly due to the sedimentation of these substances. Approximately $31 \%$ of SBOM were removed in the primary sedimentation tank; in Plant A, the level decreased to $56.50 \mathrm{mg} / \mathrm{L}$, and in Plant B, the level fell to $51.83 \mathrm{mg} / \mathrm{L}$. The concentrations of SBOM shrank in the three treatment stages of the anaerobic, anoxic and aerobic tanks, respectively, by approximately $20 \%, 12 \%$ and $30 \%$, confirming that SBOM can be degraded under anaerobic, anoxic and aerobic conditions. However, anaerobic and aerobic conditions led to higher degradation rates. Despite the short retention times of SBOM in the anaerobic tank, a significant amount was eliminated. The anaerobic tank was conducive to the hydrolysis of particulate substances. As hydrolysis is the rate-limiting step during the removal of SBOM, retention in the anaerobic tank promoted the degradation of SBOM. Therefore, according to the transformation and utilization of SBOM in anaerobic, anoxic and aerobic

Table 1

Variation along the Complete Process Flow of SBOM (mg/L).

\begin{tabular}{lll}
\hline Items & Plant A & Plant B \\
\hline Influent & $198.01 \pm 21.35$ & $178.26 \pm 20.44$ \\
Primary tank & $-57.20 \pm 5.31$ & $-62.25 \pm 6.58$ \\
Removal rate & $28.89 \%$ & $34.92 \%$ \\
Influent of Anaerobic stage & $56.50 \pm 6.32$ & $51.83 \pm 4.38$ \\
Anaerobic tank & $-11.96 \pm 1.25$ & $-11.02 \pm 1.25$ \\
Anoxic tank & $-6.10 \pm 0.63$ & $-3.55 \pm 0.42$ \\
Aerobic tank & $-12.51 \pm 1.16$ & $-13.12 \pm 1.06$ \\
Utilization rate & $54.11 \%$ & $53.32 \%$ \\
Effluent & $6.10 \pm 2.12$ & $4.37 \pm 1.08$ \\
\hline
\end{tabular}

Note: “-” stands for removal or utilization of SBOM. tanks, the retention time in the anaerobic tank may be properly increased to further intensify the utilization of SBOM.

The variation of each substrate in the biological tank was calculated based on the data from sewage treatment Plant A over one year (Table 2). In the anaerobic stage, a total of $17.81 \mathrm{mg} / \mathrm{L}$ of COD and $11.96 \mathrm{mg} / \mathrm{L}$ of SBOM were eliminated. Furthermore, $0.45 \mathrm{mg} / \mathrm{L}$ of phosphorus were released, and $9 \mathrm{mg} / \mathrm{L}$ of carbon source were consumed by the anaerobic tank (based on phosphorus release rate). In addition, $0.70 \mathrm{mg} / \mathrm{L}$ of nitrate nitrogen were removed by denitrification. Theoretically, $2.86 \mathrm{mg}$ of COD are required to reduce $1 \mathrm{mg}$ of nitrate nitrogen, approximately $2 \mathrm{mg} /$ L COD of carbon source are required for removing nitrogen through denitrification, and overall, approximately $11 \mathrm{mg} / \mathrm{L}$ COD of carbon source are consumed in the anaerobic stage. Research has shown that in the anaerobic stage, phosphorus-accumulating bacteria firstly utilize quality carbon sources, such as volatile fatty acids (VFA) and polyhydroxybutyric acid, and degrade intracellular polymeric phosphate and glycogen to increase soluble phosphorus concentrations (Xiong et al., 2012). Thus, in the anaerobic stage, RBCOD was entirely used to release phosphorus, $3.15 \mathrm{mg} / \mathrm{L}$ of SBCOD were used to release phosphorus, and all carbon sources required for nitrogen removal by denitrification were obtained from SBCOD. During the anaerobic stage, approximately $51 \%$ of carbon source in the total COD consumed served to release phosphorus, $12 \%$ was used for nitrogen removal by denitrification, and the remaining $37 \%$ was absorbed by the microbes or compounded into intracellular polymers.

There may also have been a small quantity of microbes generated (based on a reduced ammonia nitrogen content), despite a slow microbial growth rate under anaerobic conditions. In the anoxic stage, $6.10 \mathrm{mg} / \mathrm{L}$ of SBCOD and $6.11 \mathrm{mg} / \mathrm{L}$ of RBCOD were removed. Therefore, approximately $0.72 \mathrm{mg} / \mathrm{L}$ were utilized by the heterotrophic denitrifier. Furthermore, $5.26 \mathrm{mg} / \mathrm{L}$ of phosphorus were absorbed in the anoxic stage in sewage treatment Plant A. Under anoxic conditions with the presence of electron acceptors (acetic acid) and donors (nitrate nitrogen), the phosphorusaccumulating bacteria released additional phosphorus, and maintained a steady level of phosphorus in solution. However, in the anoxic stage, more phosphorus was absorbed in the presence of the electron acceptors and donors; this accounted for $65 \%$ of the total phosphorus absorption and was consistent with data observed by Zhou et al. (2013). In the aerobic stage, microbes can further metabolize through oxidizing and decomposing the remaining biodegradable substances and ammonia nitrogen in the sewage. Oxidation was readily apparent in this stage and led 

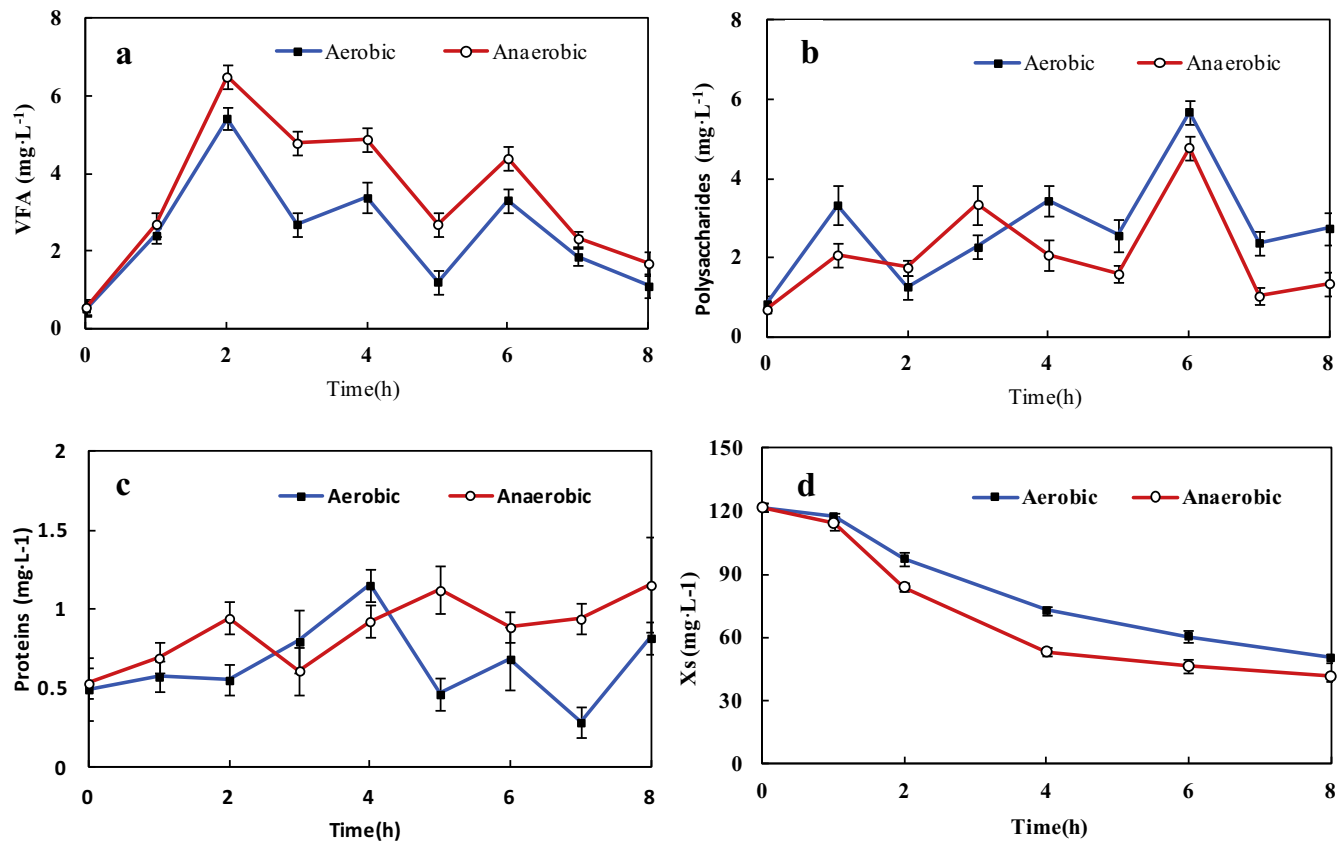

Fig. 3. Variation of VFAs (a), Polysaccharides (b), Proteins (c) and Degradation of SBOM (d) under Anaerobic and Aerobic Conditions.

Table 2

Substrate Variation of Each Reaction Stage in the Biological Tank of AAO Systems (mg/L).

\begin{tabular}{|c|c|c|c|}
\hline Measured Substance & Anaerobic Stage & Anoxic Stage & Aerobic Stage \\
\hline Consumption of slowly biodegradable organic matters & $11.96 \pm 1.35$ & $6.10 \pm 0.73$ & $12.51 \pm 1.16$ \\
\hline Consumption of rapidly biodegradable organic matter & $5.85 \pm 0.60$ & $6.11 \pm 0.58$ & $14.13 \pm 1.42$ \\
\hline Consumption/compounded amount of protein & -1.55 & -2.22 & +1.90 \\
\hline Consumption/compounded amount of polysaccharide & +1.97 & -4.19 & - \\
\hline VFAs & -7.98 & -6.02 & -7.01 \\
\hline Absorption/release of phosphorus & -0.45 & +5.26 & +2.81 \\
\hline Consumption of $\mathrm{NH}_{3}$ & 1.87 & 4.25 & 10.90 \\
\hline Reduced/generated amount of $\mathrm{NO}_{3}^{-}$ & -0.70 & +0.72 & +9.52 \\
\hline \multicolumn{4}{|l|}{ Compounded amount of microbe } \\
\hline Calculated with quality & 11.85 & 28.46 & 11.13 \\
\hline Calculated with COD & 16.83 & 40.41 & 15.80 \\
\hline
\end{tabular}

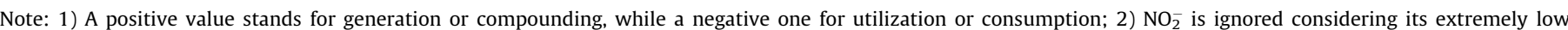
concentration; 3 ) Calculated from the nitrogen content of $12.4 \%$ according to microbial molecular formula $\mathrm{C}_{5} \mathrm{H}_{7} \mathrm{O}_{2} \mathrm{~N}$.

to rapid SBOM removal. Results indicate that approximately $26.64 \mathrm{mg} / \mathrm{L}$ of organic matter were removed in this stage and $12.51 \mathrm{mg} / \mathrm{L}$ of the hydrolysates of SBOM were oxidized, whereas the transformation rate of SBOM reached $32.52 \%$.

\subsection{Transformation characteristics of SBOM}

To identify the transformation characteristics of SBOM, the slowly biodegradable particulate organic matter in raw sewage was examined and the DOM values in the reactors were determined for the aerobic and anaerobic conditions in the simulation test (Maqbool et al., 2016; Hulatt et al., 2010). The results are shown in Fig. 3.

Fig. 3a illustrates that the variations in VFAs under aerobic and anaerobic conditions were similar, and the VFA concentration was higher in the anaerobic scenario. The VFA concentrations under the two conditions significantly increased during the first $2 \mathrm{~h}$, indicating that SBOM hydrolyzed and fermented so that the formation rate was higher than the consumption rate of VFAs, i.e. VFAs accumulation. As the reaction continued, the VFA formation rate gradually decreased to a lower level than that of the consumption rate of microbes, resulting in decreased VFA concentrations.
As shown in Fig. 3b, the polysaccharide concentrations varied similarly like those of the VFAs. Macromolecular and particulate substances diffused onto cell surfaces and were extracellularly hydrolyzed to produce hydrolysates, which were then released. This process was repeated until hydrolysate molecular weights decreased below $1000 \mathrm{Da}$, at which point they could be absorbed and utilized by the microbes. Consequently, the concentrations of polysaccharide reached a dynamic equilibrium. The protein contents increased under anaerobic conditions and remained extremely low under aerobic conditions (Fig. 3c). Most proteins were hydrolyzed within $10 \mathrm{~min}$ under anaerobic or aerobic conditions and were absorbed by microbes before being decomposed into soluble amino acids. The formation of polysaccharides and proteins indicates that SBOM were utilized as carbon sources to provide energy and substrates for aerobic and anaerobic metabolism.

Fluorescent spectroscopy was used to further analyze the decomposition products of SBOM. Fig. 4 shows the 3D fluorescence contour spectra for the DOM of the anaerobic and aerobic reactors. According to the data in Fig. 4 and Table 3, two fluorescence peaks, peak A (250-400 nm/260-380 nm) and peak B (310-360 nm/ 370$450 \mathrm{~nm})$, were observed. Peaks A and B represented tyrosine-like and fulvic acid-like fluorescence peaks, respectively. 

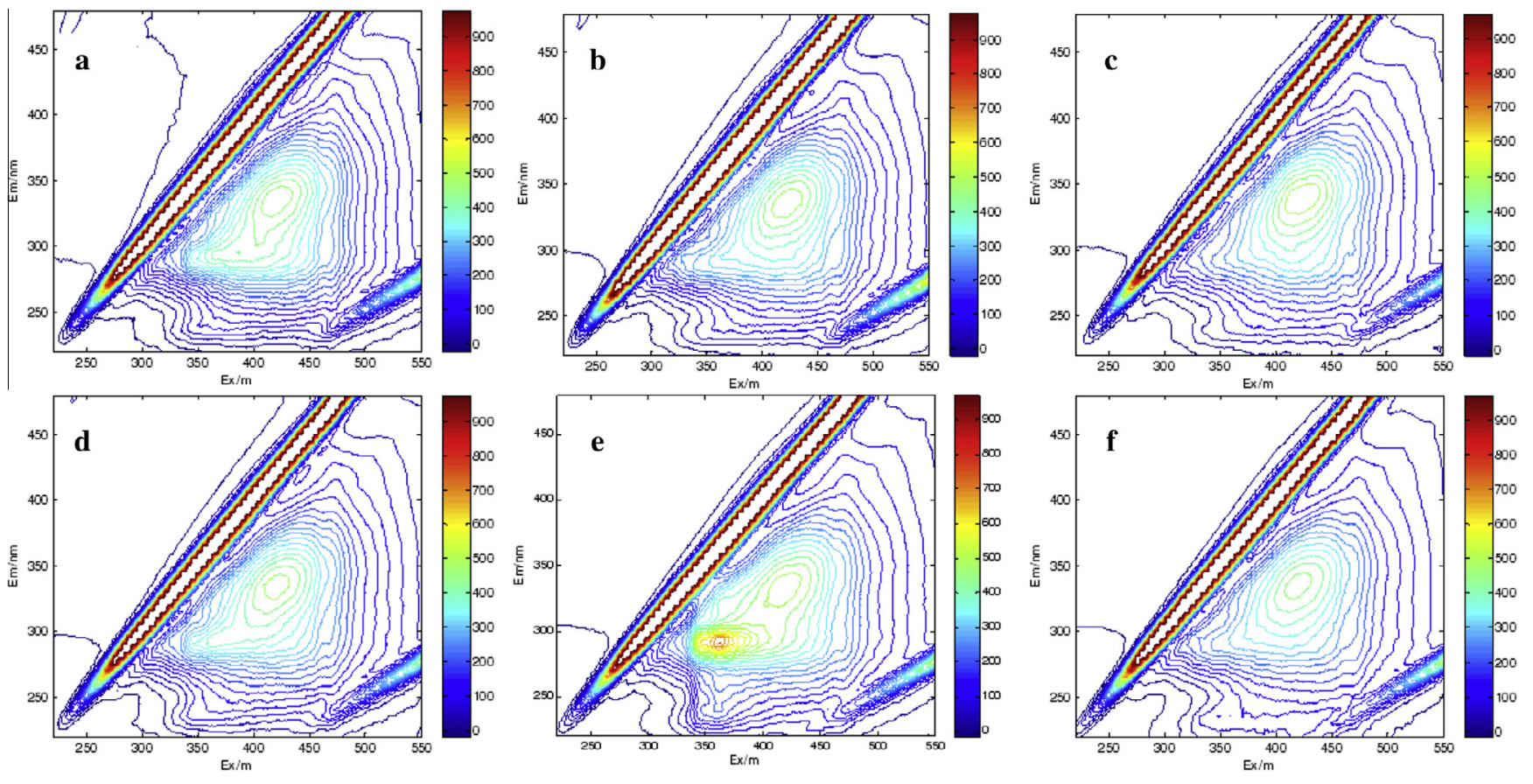

Fig. 4. 3D Fluorescence Spectrum for DOM aerobic duration of $2 \mathrm{~h} \mathrm{(a),} 4 \mathrm{~h}$ (b) and $8 \mathrm{~h}$ (c); anaerobic duration of $2 \mathrm{~h}(\mathrm{~d}), 4 \mathrm{~h}(\mathrm{e})$ and $8 \mathrm{~h}$ (f).

Table 3

3D Fluorescence Characteristics of DOM.

\begin{tabular}{|c|c|c|c|c|c|c|c|c|}
\hline & \multicolumn{4}{|c|}{ Aerobic Condition } & \multicolumn{4}{|c|}{ Anaerobic Condition } \\
\hline & \multicolumn{2}{|c|}{$\begin{array}{l}\text { Tyrosine-like fluorescence } \\
\text { peak A }\end{array}$} & \multicolumn{2}{|c|}{$\begin{array}{l}\text { Fulvic-acid-like } \\
\text { fluorescence peak B }\end{array}$} & \multicolumn{2}{|c|}{$\begin{array}{l}\text { Tyrosine-like fluorescence } \\
\text { peak A }\end{array}$} & \multicolumn{2}{|c|}{$\begin{array}{l}\text { Fulvic-acid-like } \\
\text { fluorescence peak B }\end{array}$} \\
\hline & $\operatorname{Ex} / \operatorname{Em}(\mathrm{nm})$ & $I$ & $\operatorname{Ex} / \operatorname{Em}(\mathrm{nm})$ & $I$ & $\operatorname{Ex} / \operatorname{Em}(\mathrm{nm})$ & $I$ & $\operatorname{Ex} / \operatorname{Em}(\mathrm{nm})$ & $I$ \\
\hline $0 \mathrm{~h}$ & $290 / 362$ & 206 & $335 / 420$ & 338 & $290 / 362$ & 206 & $335 / 420$ & 338 \\
\hline $2 \mathrm{~h}$ & $295 / 380$ & 433 & $335 / 421$ & 470 & $295 / 380$ & 433 & $335 / 425$ & 478 \\
\hline $4 \mathrm{~h}$ & & & $335 / 421$ & 484 & $290 / 362$ & 716 & $335 / 420$ & 495 \\
\hline $8 \mathrm{~h}$ & & & $340 / 422$ & 498 & & & $335 / 422$ & 463 \\
\hline
\end{tabular}

Table 4

Fluorescence Indices $\mathrm{f} 450 / 500$ and $\lambda 0.5$ of DOM.

\begin{tabular}{|c|c|c|c|c|c|c|c|c|}
\hline & \multicolumn{4}{|c|}{ Aerobic Condition } & \multicolumn{4}{|c|}{ Anaerobic Condition } \\
\hline & $0 \mathrm{~h}$ & $2 \mathrm{~h}$ & $4 \mathrm{~h}$ & $8 \mathrm{~h}$ & $0 \mathrm{~h}$ & $2 \mathrm{~h}$ & $4 \mathrm{~h}$ & $8 \mathrm{~h}$ \\
\hline $\mathrm{f}_{450 / 500}$ & 2.04 & 2.05 & 2.08 & 2.10 & 2.04 & 2.06 & 2.09 & 2.05 \\
\hline$\lambda_{0.5} / \mathrm{nm}(\mathrm{Ex}=280 \mathrm{~nm})$ & 335 & 325 & 306 & 327 & 335 & 314 & 333 & 307 \\
\hline$\lambda_{0.5} / \mathrm{nm}(\mathrm{Ex}=320 \mathrm{~nm})$ & 347 & 352 & 355 & 356 & 347 & 352 & 344 & 354 \\
\hline$\lambda_{0.5} / \mathrm{nm}(\mathrm{Ex}=370 \mathrm{~nm})$ & 398 & 396 & 396 & 399 & 398 & 397 & 395 & 396 \\
\hline
\end{tabular}

The results show that during the reactions, there were significant changes in the central positions and peak intensities of the DOM fluorescence peaks. Furthermore the DOM changes were similar under aerobic and anaerobic conditions. The peak $A$ intensities initially increased but disappeared after $4 \mathrm{~h}$ under aerobic treatment or $8 \mathrm{~h}$ under anaerobic treatment. Peak A represents the proteinoid substances, i.e. types of biodegradable substances which initially had formation rates greater than consumption rates, increasing the proteinoid content. Subsequently, the consumption rates were greater than the formation rates. During the reactions, slight red shifts occurred at the central positions of peak A as proteinoid substances were transformed by microbes into inorganic matter, cellular substances and other non-biodegradable substances, such as humus. Peak B intensities increased. Peak B represents non-biodegradable humus-type substances which are difficult to biodegrade and readily accumulate. However, red shifts also occurred at the central positions of peak $\mathrm{B}$, indicating that the carbonyl, carboxyl, hydroxyl and amino contents of resolvable fulvic acid-like substances increased. Humus acid, while stable, may have been structurally altered under prolonged microbial action.

Table 4 shows the fluorescence indices for DOM during the reaction. According to Table 4 , the fluorescence indices $f_{450 / 500}$ of all DOMs were within 2.04-2.10, i.e. organic matter of microbial origins significantly contributed to the resolvable humus-type substances. Most of the humus-type substances with fluorescence groups were produced from microbe metabolic processes. The fluorescence index $\lambda_{0.5}$ varied and depended on the excitation wavelength. When the excitation wavelength was $280 \mathrm{~nm}$, a significant change occurred in the value of $\lambda_{0.5}$. When the excitation wavelength was $320 \mathrm{~nm}$ or $370 \mathrm{~nm}$, no increasing or decreasing trends 
in the values of $\lambda_{0.5}$ were observed and were approximately $350 \mathrm{~nm}$ or $390 \mathrm{~nm}$. The data indicated that the value of $\lambda_{0.5}$ $\left(\lambda_{\mathrm{ex}}=280 \mathrm{~nm}\right)$ correlated with the number of conjugated bonds in the aromatic ring and alkyl chain of humus acid. The gradual decrease of this value indicated that the humus acid organic structure tended to be saturated. Furthermore, this was linked with the microbes' biochemical reactions.

\subsection{Analysis on utilization potential of SBOM}

To study the utilization potential of SBOM, transformations of SBOM under anaerobic and aerobic conditions were analyzed and evaluated by determining the changes in quality of particulate SBOM (Fig. 3d). Fig. 1d shows three stages and in the first stage the rate-limiting stage is depicted. A few studies have asserted that SBOM cannot be directly utilized by microbes unless they are firstly hydrolyzed into readily biodegradable organic matter. Thus, the curves have an initial gentle downward trend (Fig. 3d, 0-1 h). In the second stage, the downward trend sharply increased. As the SBOM hydrolyzed, the amount of micromolecular substances in the reactor increased and were consumed by microbes. This resulted in a decreased concentration of SBOM. In the final stage, the curves plateaued because the SBOM had degraded. The results indicate that the concentrations of SBOM decreased under anaerobic and aerobic conditions, whilst the SBOMs likely transformed into useful carbon sources to microbes.

Under anaerobic conditions, SBOM only decreased $7.43 \mathrm{mg} / \mathrm{L}$ within $1 \mathrm{~h}$. It is evident in Fig. $3 \mathrm{~d}$ that the amount of dissolvable substances increased, indicating SBOM were hydrolyzed into smaller, more readily biodegradable organic matter. The concentration of SBOM dramatically decreased from 1 to $4 \mathrm{~h}$. However, according to the VFAs, protein and polysaccharide analyses, no equivalent increase was observed for the DOM. The data shows that the formation rate of hydrolysates of SBOM were lower than the consumption rate of the microbes, suggesting that the easilydegradable substrates, such as VFAs, produced from the hydrolysis of SBOM were directly utilized by the microbes. The flattening of the curves in the final stage indicated that the degradation rates of the remaining SBOM were extremely low after $4 \mathrm{~h}$ of anaerobic hydrolysis. The decreasing VFA concentrations in this stage also reflected the extremely low formation rate of readily biodegradable organic matter from the hydrolysis of the SBOM. Thus the degradation of SBOM could not be further improved even with prolonged anaerobic treatment.

The degradation processes under aerobic and anaerobic conditions were similar. The degradation rate during $0-1 \mathrm{~h}$ was extremely low, and the concentration of SBOM only fell by $3.6 \%$. The primary reaction during this stage was hydrolysis, and the hydrolysates were primarily micromolecular VFAs, accounting for more than $80 \%$ of the DOM. One hour later, the degradation curve for the SBOM decreased rapidly. The smaller quantities for the durations of $2-4 \mathrm{~h}, 4-6 \mathrm{~h}$ and $6-8 \mathrm{~h}$ were $24.59 \mathrm{mg} / \mathrm{L}, 12.20 \mathrm{mg} / \mathrm{L}$ and $10.26 \mathrm{mg} / \mathrm{L}$, respectively, indicating that under aerobic conditions, the degradation rate of SBOM remained at high levels before decreasing during the reaction. Overall, the utilization rate of SBOM under aerobic conditions was slightly lower than that under anaerobic conditions. In this experiment, the utilization rate of SBOM was $65 \%$ while the other $35 \%$ remained unutilized. However, in a practical sewage treatment system, the remaining SBOM primarily exist in particulate form and are either separated with activated sludge or returned to the biological treatment system.

To study the denitrification and utilization of SBOM under anaerobic conditions, the following experiment was carried out. Particulate organic matter, DOM sourced from sewage (filtered through $0.45-\mu \mathrm{m}$ filters) and sodium acetate (all having the same COD) were mixed for small-scale tests. $\mathrm{KNO}_{3}$ was added to the mixture to maintain a nitrate nitrogen concentration of approximately $40 \mathrm{mg} / \mathrm{L}$. The reaction was executed under anaerobic conditions for $8 \mathrm{~h}$. The denitrification performance and utilization of denitrifying carbon sources under anaerobic conditions were analyzed, and the results are shown in Fig. 5.

The nitrate concentrations of DOM and sodium acetate decreased by $16.64 \mathrm{mg} / \mathrm{L}$ and $23.76 \mathrm{mg} / \mathrm{L}$, respectively, at $1 \mathrm{~h}$ (before the reaction). However, the concentration of particulate organic matter slightly decreased by only $0.59 \mathrm{mg} / \mathrm{L}$. This is because DOM and sodium acetate constitute easily biodegradable organic matter, and are more easily utilized by microbes compared with those of particulate organic matter. Particulate organic matter can only be utilized by microbes after hydrolysis. Two hours later, the nitrate curve in the reactor with sodium acetate plateaued because the depletion of sodium acetate inhibits denitrification. The nitrate trend slightly decreased in the reactor with DOM as the easily biodegradable organic matter in the DOM had been degraded. The residual SBOM decelerated the removal rate of nitrate nitrogen. The concentration of nitrate in the reactor with particulate organic matter dropped rapidly over $1-4 \mathrm{~h}$ before plateauing. After $8 \mathrm{~h}$ of reaction, the quantities of the three removed carbon sources were $32.38 \mathrm{mg} / \mathrm{L}, 26.63 \mathrm{mg} / \mathrm{L}$ and $20.52 \mathrm{mg} / \mathrm{L}$, respectively, with nitrate and sodium acetate recording the best denitrification performance, followed by DOM. During the first hour, the quantities of CODs consumed by the three carbon sources were $73.85 \mathrm{mg} / \mathrm{L}, 53.12 \mathrm{mg} / \mathrm{L}$ and $6.43 \mathrm{mg} / \mathrm{L}$, respectively, and accordingly, the utilization rates of denitrification were $92.02 \%, 89.79 \%$ and $21.78 \%$. After $8 \mathrm{~h}$ of reaction, the utilization rates of denitrification of the three carbon sources were $89.91 \%, 85.58 \%$ and $73.2 \%$, respectively. Based on this data, the denitrification and utilization of the denitrifying carbon sources of particulate organic matter were similar to those of the other two
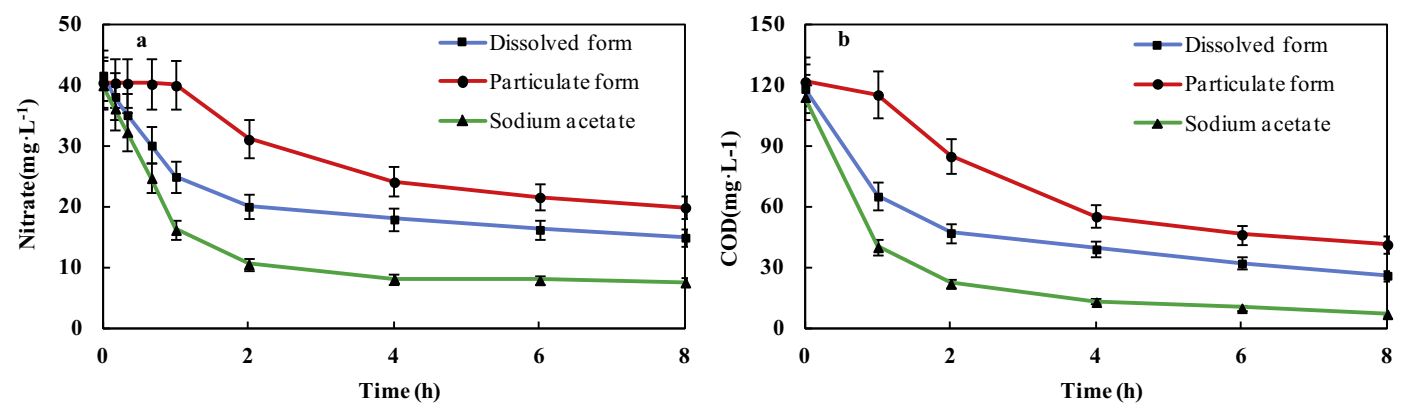

Fig. 5. (a) Variation of Nitrate Concentration under Different Carbon Source Conditions and (b) COD Variation of Different Carbon Sources under Anaerobic Condition. 
Table 5

UV Characteristic Values of DOM.

\begin{tabular}{|c|c|c|c|c|c|c|c|c|c|}
\hline Measured indexes & $0 \mathrm{~h}$ & $1 \mathrm{~h}$ & $2 \mathrm{~h}$ & $3 \mathrm{~h}$ & $4 \mathrm{~h}$ & $5 \mathrm{~h}$ & $6 \mathrm{~h}$ & $7 \mathrm{~h}$ & $8 \mathrm{~h}$ \\
\hline SUVA $_{254}$ & 0.77 & 0.67 & 0.49 & 0.37 & 0.65 & 0.86 & 0.55 & 0.61 & 0.52 \\
\hline $\mathrm{A}_{253} / \mathrm{A}_{203}$ & 1.04 & 1.02 & 1.03 & 1.03 & 1.03 & 1.02 & 1.02 & 1.03 & 1.02 \\
\hline $\mathrm{E}_{4} / \mathrm{E}_{6}$ & 0.70 & 1.18 & 1.20 & 1.21 & 1.18 & 1.18 & 1.21 & 1.20 & 1.20 \\
\hline
\end{tabular}

carbon sources. With enough time and proper conditions, particulate carbon sources can be employed as useful carbon sources for improving nitrogen and phosphorus removal.

\subsection{Conversion mechanism of SBOM}

\subsubsection{Ultraviolet spectrum}

Table 5 shows the characteristic UV absorbance of DOMs. SUVA $_{254}$ is the specific value of absorbance and solution concentration at $254 \mathrm{~nm}$ and represents the degree of aromatization, molecular weight and humification level of organic matter. The SUVA 254 value of organic matter reflects different extents of the components, degree of aromatization and biochemical characteristics of organic matter in the system. A higher $\mathrm{SUVA}_{254}$ indicates there is greater aromatization, a higher molecular weight and more unsaturated double bonds or aromatic groups in organic matter. As shown in Table 5 , the $\mathrm{SUVA}_{254}$ slightly reduced in the initial stage of the reaction, showing a significant quantity of aromatic substances and a significant amount of organic matter with high molecular weights. From 1 to $3 \mathrm{~h}$, the $\mathrm{SUVA}_{254}$ rapidly reduced. Based on the results presented in Section 3.1, it is known that the concentration of SBOM rapidly reduced at this time, and most of the slowly macromolecule biodegradable organic matters were hydrolyzed into smaller substances, leading to a rapid reduction of the $\mathrm{SUVA}_{254}$. After $4 \mathrm{~h}$, the $\mathrm{SUVA}_{254}$ tended to gradually reduce with fluctuations, proving the structural framework and functional groups may have changed or a new organic metabolite may have been generated during the reaction. With respect to the overall process, the trend for $\mathrm{SUVA}_{254}$ to decrease in organic matter indicates that the organic matter in the reactor: firstly, altered structural characteristics; secondly, reduced degrees of aromatization and humification levels; and thirdly, lowered molecular weights.

Specific values of $A_{253}$ and $A_{203}$ represent the substitution degrees of aromatic rings and the types of substituting group. A lower value indicates that the substituting groups in the aromatic rings are mainly aliphatic chains, while a higher value represents functional groups having higher contents of carbonyl, carboxyl, and hydroxyl group and esters. The experiment's results showed relatively high specific values of $\mathrm{A}_{253}$ and $\mathrm{A}_{203}$, with only slight reductions. This outcome indicates that in the reaction, there are high contents of oxygen-containing functional groups (e.g., hydroxyl, carbonyl, and carboxyl groups and esters) in the substituting groups of the aromatic rings. With reference to the threedimensional fluorescence results, SBOM generate degradationresistant substances during their transformation. Furthermore, a few of these substances restructure after microbial action, leading to more oxygen-containing functional groups within the substituting groups. Moreover, after $8 \mathrm{~h}$ of reaction the DOM content in the reactor slightly reduced to simpler compositions.

The $E_{4} / E_{6}$ value, i.e. the specific value of the absorbance of $465 \mathrm{~nm}$ and $665 \mathrm{~nm}$, reflects the polymerization degree of a benzene ring $C$ framework with the lower value indicating a higher polymerization degree of organic matter. Additionally, $\mathrm{E}_{4} / \mathrm{E}_{6}$ is also related to $\mathrm{pH}$, the content of $-\mathrm{COOH}$ in the organic matter and the overall acidity. As shown in Table 5 , as $\mathrm{E}_{4} / \mathrm{E}_{6}$ gradually increases as the reaction continues, it became increasingly evident that less molecule polymerization of the DOMs occurred in the reactor.

\subsubsection{Distribution of molecular weight}

To further differentiate the altered components in the reactor and understand the degradation mechanism of SBOM, this study used high-performance size exclusion chromatography to analyze and determine the molecular weight distribution of DOMs during the reaction process. The $U_{254}$ value represents the change of humus-type macromolecular organic compounds and aromatic compounds containing $\mathrm{C}=\mathrm{C}$ and $\mathrm{C}=\mathrm{O}$ double bonds in the DOMs. 3D fluorescence spectra reveal that the organic matters have peaks at $\mathrm{Ex} / \mathrm{Em}=285 / 335$ and 230/335. Tyrosine and tryptophan substances, i.e. proteinoid substances in the DOMs in the reactor were characterized. Two strong absorption peaks A and B exist at $11.7 \mathrm{~min}$ and $12.3 \mathrm{~min}$, respectively, with corresponding molecular weights of $22.6 \mathrm{kDa}$ and $11.2 \mathrm{kDa}$. Additionally, since there is a weak UV absorption peak from 14 to $17 \mathrm{~min}$ ( $\mathrm{MW}=44 \mathrm{Da}-$ $1.5 \mathrm{kDa}$ ), humus-type macromolecular organic and aromatic compounds containing $\mathrm{C}=\mathrm{C}$ and $\mathrm{C}=\mathrm{O}$ double bonds were relatively stable. During the reaction, the molecular weight distributions of DOMs in the reactor were mostly similar except for a significant difference. A significant change in the response strength of the peak-generating substances was observed for the macromolecular substances represented by peaks $A$ and $B$. In particular peak $A$ slightly shifted to the right, and the corresponding response strength of substances with peak A showed a slightly increasing trend in the few hours at the beginning of the reaction that subsequently slightly decreased. A few of the macromolecular substances represented by peak A migrated and transformed into substances with different molecular weights during the reaction. While the macromolecular substances represented by peak $B$ are relatively stable, the response strength of peak B constantly changed during the reaction and reached its highest at $8 \mathrm{~h}$. The response strength of the absorption peak gradually increased from 16 min $(\mathrm{MW}=144 \mathrm{Da})$ and reached a maximum at $7 \mathrm{~h}$.

This result indicates that the decomposition rate of certain macromolecular substances to such substances is greater than the migration and transformation rates of these substances to other substances, which leads to the increase of such substances. A new absorption peak was also detected during the reaction, i.e. a weak UV absorption peak at $7 \mathrm{~min}$ in the $4 \mathrm{~h}$ stage. From the above analysis, during the reaction a few macromolecular humus-type organic compounds and aromatic compounds migrated and transformed into substances with different molecular weights, and furthermore micromolecular substances accumulated. Therefore, long hours of microbial action increased the proportion of micromolecular substances as time passed.

To this end, at $254 \mathrm{~nm}, \mathrm{Ex} / \mathrm{Em}=230 / 335$ and 285/335 were respectively used to characterize the molecular weight distributions of DOMs by UV and fluorescence detectors. Generally, the molecular weight of proteinoid substances mainly concentrated at peaks $A$ and $B$ during the reaction, which means that it was relatively stable. Increased response strength of peak A detected during the reaction indicates that the decomposition rate of certain macromolecular substances to such substances was higher than the migration and transformation rate of such substances to other substances, which leads to an increase in such substances. Many new absorption peaks were detected in the medium term of the reaction. Most proteins, micromolecular organic acids and other 
organic matters are readily biodegradable substances and will likely be transformed and removed after being compounded to other mesostates or biologically decomposed into water and $\mathrm{CO}_{2}$. It was observed from the above analysis that: firstly, the molecular weights of proteinoid substances are widely distributed during the reaction; and secondly, proteinoid substances with high molecular weights tended to decrease over time.

\section{Conclusions}

About $20 \% \sim 30 \%$ of carbon source is lost in the primary settling tank of sewage plants (mainly SBOM). Under anaerobic/aerobic conditions, SBOM can be transformed into more readily biologically utilized substrates, such as VFAs, polysaccharides and proteins. Most of SBOM can be hydrolyzed into dissolved matter with transformation rates reaching approximately 65\% within $8 \mathrm{~h}$ which can greatly improve the efficiency of nitrogen removal. A few macromolecular humus-type organic compounds and aromatic compounds could be migrated and transformed into substances with different molecular weights.

\section{Acknowledgements}

This study was supported by the National Natural Science Foundation of China (Grant No. 51508447, 51508451), the National High Technology Research and Development Program of China (Grant No. 2011AA060903) and Program for Innovative Research Team in Shaanxi (PIRT) (Grant No. 2013KCT-13). The authors are also very grateful for the collaboration between University of Technology Sydney (UTS) and Xi"an University of Architecture and Technology (XAUAT).

\section{Appendix A. Supplementary data}

Supplementary data associated with this article can be found, in the online version, at http://dx.doi.org/10.1016/j.biortech.2016.06. 068.

\section{References}

Chon, K., Park, J., Cho, J., 2013. Humification of effluent organic matters through a surface-flow constructed wetland. Water Sci. Technol.: J. Int. Assoc. Water Pollut. Res. 8 (68), 1785-1794.

Drewnowski, J., Makinia, J., 2011. The role of colloidal and particulate organic compounds in denitrification and EBPR occurring in a full-scale activated sludge system. Water Sci. Technol. 63 (2), 318-324.

Gao, Y.Q., Peng, Y.Z., Zhang, J.Y., Wang, J.L., Ye, L., 2010. Using excess sludge as carbon source for enhanced nitrogen removal and sludge reduction with hydrolysis technology. Water Sci. Technol.: J. Int. Assoc. Water Pollut. Res. 7 (62), 1536-1543.

Hong, S.W., Choi, Y.S., Kwon, G., Park, K.Y., 2005. Performance evaluation of physicochemical processes for biologically pre-treated livestock wastewater. Water Sci. Technol.: J. Int. Assoc. Water Pollut. Res. 10-11 (52), 107-115.

Hulatt, Chris J., Thomas, David N., 2010. Dissolved organic matter (DOM) in microalgal photobioreactors: a potential loss in solar energy conversion? Bioresour. Technol. 101, 8690-8697.

Ikumi, D.S., Harding, T.H., Ekama, G.A., 2014. Biodegradability of wastewater and activated sludge organics in anaerobic digestion. Water Res. 56 (1), 267-279.

Jensen, P.D., Hardin, M.T., Clarke, W.P., 2009. Effect of biomass concentration and inoculum source on the rate of anaerobic cellulose solubilization. Bioresour. Technol. 21 (100), 5219-5225.

Ji, Z.Y., Chen, G.L., Chen, Y.G., 2010. Effects of waste activated sludge and surfactant addition on primary sludge hydrolysis and short-chain fatty acids accumulation. Bioresour. Technol. 101 (10), 3457-3462
Jin, P.K., Chang, J., Wang, X.B., Liu, K.J., Wang, X.C., 2014. Variation of different carbon sources in the sewage treatment process. J. Environ. Sci. 9 (35), $3443-$ 3448 .

Jin, P., Wang, B., Jiao, D., Sun, G., Wang, B., Wang, X.C., 2015. Characterization of microflora and transformation of organic matters in urban sewer system. Water Res. 84 (1), 112-119.

Jordao, C.P., Pereira, M.G., Bellato, C.R., Pereira, J.L., Matos, A.T., 2002. Assessment of water systems for contaminants from domestic and industrial sewages. Environ. Monit. Assess. 79 (1), 75-100.

Katsuki Kimura, Nishimura, Shin-Ichiro, Miyoshi, Risho, Hoque, Asiful, Miyoshi, Taro, Watanabe, Yoshimasa, 2015. Application of glyco-blotting for identification of structures of polysaccharides causing membrane fouling in a pilot-scale membrane bioreactor treating municipal wastewater. Bioresour. Technol. 179, 180-186.

Lee, Y.H., Chung, Y.C., Jung, J.Y., 2008. Effects of chemical and enzymatic treatments on the hydrolysis of swine wastewater. Water Sci. Technol.: J. Int. Assoc. Water Pollut. Res. 7 (58), 1529-1534.

Liu, S.G., Ni, B.J., Li, W.W., Sheng, G.P., Tang, Y., Yu, H.Q., 2011. Modeling of the Contact-Adsorption-Regeneration (CAR) activated sludge process. Bioresour. Technol. 3 (102), 2199-2205.

Liu, H., Zhao, F., Mao, B., Wen, X., 2012. Enhanced nitrogen removal in a wastewater treatment process characterized by carbon source manipulation with biological adsorption and sludge hydrolysis. Bioresour. Technol. 114, 62-68.

Liu, Z.H., Lu, G.N., Yin, H., Dang, Z., Rittmann, B., 2015. Removal of natural estrogens and their conjugates in municipal wastewater treatment plants: a critical review. Environ. Sci. Technol. 9 (49), 5288-5300.

Ma, W., Yang, M., Wang, J., Qi, R., Ren, L., 2002. Treatment of antibiotics wastewater utilizing successive hydrolysis, denitrification and nitrification. Environ. Technol. 6 (23), 685-694.

Maqbool, Tahir, Quang, Viet Ly, Cho, Jinwoo, Hur, Jin, 2016. Characterizing fluorescent dissolved organic matter in a membrane bioreactor via excitation-emission matrix combined with parallel factor analysis. Bioresour. Technol. 209, 31-39.

McDowell, W.H., Zsolnay, A., Aitkenhead-Peterson, J.A., Gregorich, E.G., Jones, D.L., Jödemann, D., et al., 2006. A comparison of methods to determine the biodegradable dissolved organic carbon from different terrestrial sources. Soil Biol. Biochem. 7 (38), 1933-1942.

Munoz, C., Young, H., Antileo, C., Bornhardt, C., 2009. Sliding mode control of dissolved oxygen in an integrated nitrogen removal process in a sequencing batch reactor (SBR). Water Sci. Technol.: J. Int. Assoc. Water Pollut. Res. 10 (60), 2545-2553.

Nikos Vakondios, Koukouraki, Elisavet E., Diamadopoulos, Evan, 2014. Effluent organic matter (EfOM) characterization by simultaneous measurement of proteins and humic matter. Water Res. 63, 62-70.

Raunkjaer, K., Jacobsen, T.H., Nielsen, P.H., 1994. Measurement of pools of protein, carbohydrate and lipid in domestic wastewater. Water Resour. 28, 251-262.

Roeleveld, P.J., van Loosdrecht, M.C.M., 2002. Experience with guidelines for wastewater characterization in the Netherlands. Water Sci. Technol. 45 (6), 77-87.

Tas, D.O., Karahan, O., Insel, G., Ovez, S., Orhon, D., Spanjers, H., 2009. Biodegradability and denitrification potential of settleable chemical oxygen demand in domestic wastewater. Water Environment Research: a research publication of the Water Environment Federation 7 (81), 715-727.

Tran, N.H., Ngo, H.H., Urase, T., Gin, K.Y., 2015. A critical review on characterization strategies of organic matter for wastewater and water treatment processes. Bioresour. Technol. 193, 523-533.

Ubay Cokgor, E., Sozen, S., Insel, G., Orhon, D., 2009. Respirometric evaluation of biodegradation characteristics of dairy wastewater for organic carbon removal. Environ. Technol. 11 (30), 1169-1176.

Wang, Y., Guo, G., Wang, H., Stephenson, T., Guo, J., Ye, L., 2013. Long-term impact of anaerobic reaction time on the performance and granular characteristics of granular denitrifying biological phosphorus removal systems. Water Res. 14 (47), 5326-5337.

Wichern, M., Kehl, O., Erbe, V., Luebken, M., Wilderer, P.A., 2006. Modelling COD and $\mathrm{N}$ removal in the water and in the benthic biofilm for the River Wupper in Germany. Water Sci. Technol.: J. Int. Assoc. Water Pollut. Res. 10 (53), 163-171.

Wu, X., Yang, Y., Wu, G., Mao, J., Zhou, T., 2016. Simulation and optimization of a coking wastewater biological treatment process by activated sludge models (ASM). J. Environ. Manage. 165, 235-242.

Xiong, H.L., Chen, J.L., Wang, H., Shi, H.C., 2012. Influences of volatile solid concentration, temperature and solid retention time for the hydrolysis of waste activated sludge to recover volatile fatty acids. Bioresour. Technol. 119, 285292.

Zhou, M., Gong, J.Y., Yang, C.Z., Pu, W.H., 2013. Simulation of the performance of aerobic granular sludge SBR using modified ASM3 model. Bioresour. Technol. $127,473-481$

Zhu, S., Hua, T., Zhou, Q.X., Wu, Q., 2009. Ecological safety regulation of A/DAT-IAT process for municipal wastewater treatment. J. Appl. Ecol. 5 (20), 1209-1213. 